\title{
PRESENTASI TOKOH ESTELLE DALAM NASKAH PINTU TERTUTUP KARYA JEAN PAUL SARTRE TERJEMAHAN ASRUL SANI DENGAN MENGGUNAKAN TEORI PSIKOANALISIS
}

\author{
Eyes Christa Ramadhandi Putri \\ Institut Seni Indonesia Yogyakarta
}

\begin{abstract}
Abstrak: Naskah yang akan digunakan dalam studi pemeranan ini adalah Pintu Tertutup karya Jean Paul Sartre yang diterjemahkan Asrul Sani dari judul asli Huis Clos (1945). Studi pemeranan ini akan menggunakan pendekatan presentasi (realis) sebagai metode analisis naskah, mengolah dialog dan transformasi aktor. Analisis karakter yang digunakan sebagai basis eksplorasi peran adalah menggunakan teori psikoanalisis Freud. Hasil dari studi karakter dan naskah memungkinkan pemeran dalam memerankan tokoh secara penuh perasaan, kuat dan ekspresif.
\end{abstract}

Kata kunci: presentation, realis, transformasi, psikoanalisis

\begin{abstract}
The playscript used in this characterization study is the Pintu Tertutup, the work of Jean-Paul Sartre, translated by Asrul Sani from the original title Huis Clos (1945). This study used the presentation (realist) approach as a method of character creation, dialogue and transforming actors. Character analysis used as the basis for role exploration using Freud's psychoanalytic theory. The results of character and playscript analysis enable the actor to impersonate the character in a full, strong and expressive feeling.
\end{abstract}

Key words: presentation, realist, transformation, psychoanalysis

\section{Pendahuluan}

Naskah Pintu Tertutup adalah naskah karya Jean Paul Sartre yang telah diterjemahkan Asrul Sani dari judul asli Huis Clos (1945). Pintu Tertutup bercerita tiga orang yang masuk ke dalam neraka dalam kondisi tidak saling mengenal. Mereka adalah seorang laki-laki bernama Garcin yang mati karena ditembak dua belas peluru, seorang wanita bernama Inez yang mati karena gas dan seorang wanita bernama Estelle dari Prancis yang mati karena radang paru-paru.

Tokoh Estelle menjadi orang yang terakhir masuk ke dalam neraka dan tidak menerima jika dirinya disebut orang mati. Estelle memiliki rasa takut yang amat dalam karena dirinya telah membunuh anaknya yang baru lahir dan membuat orang yang memberinya anak bunuh diri. Estelle tidak ingin jika Garcin dan Inez tahu bahwa dirinya melakukan hal tersebut. Di hadapan mereka, Estelle berusaha sekuat tenaga untuk menutupi kesalahannya dan bersikap acuh seperti wanita kaya yang harus dilayani.

Karakter Estelle dalam naskah ini sangat menarik sebab sebagai seseorang yang dulunya miskin akhirnya bangkit dari kemiskinan karena menikahi laki-laki kaya. Menjalani kehidupan sebagai orang kaya tentu membuat Estelle akhirnya harus pandai berbicara dengan orang banyak. Kepandaian berbicara ini terletak pada kejelian membaca latar belakang atau kesukaan lawan bicara. Seperti yang terjadi dalam naskah ketika Inez menanyakan kembali kenapa mereka bisa sampai ke 
neraka. Maka dengan cepat Estelle menutupi kegugupannya dan menjawab bahwa dirinya berada di neraka karena kesalahan administrasi. Karakter Estelle ini semakin menarik sebab dia mengerti cara membuat laki-laki menuruti kemauannya.

Karakter yang menarik ini juga didukung dengan alur yang menarik sebab dalam naskah ketiga tokoh ini telah mati dan Estelle harus menerima kenyataan pahit bahwa sahabat karibnya tidak menangisi kematiannya. Bahkan suaminya sendiri tidak datang ke acara pemakamannya. Tidak hanya itu, sahabatnya juga berani mengungkapkan perbuatannya kepada anak muda yang merupakan pacar Estelle. Anak muda yang menjadi satu-satunya harapan Estelle agar selalu mengingat dirinya dengan baik juga pada akhirnya harus pupus. Kini Estelle tidak memiliki orang yang mengasihinya lagi, tidak ada yang bisa dibanggakan dari dirinya. Rasa itulah yang dicemaskan oleh Estelle, sehingga dia mencari orang yang bisa membantunya. Garcin sebagai satu-satunya laki-laki di ruangan itulah yang akhirnya menjadi target Estelle karena Inez pasti tidak bisa dia kuasai.

Segala tingkah laku Estelle yang diawal kemunculannya penuh dengan kesombongan pada akhirnya runtuh dan memperlihatkan karakter yang rapuh tetapi kemudian karakter Estelle berubah lagi menjadi lebih berani di akhir cerita. Karakter yang berubah-ubah dengan latar kehidupan wanita dari Paris enam tahun telah menjalani kehidupan sosial yang tinggi ini begitu menantang untuk dimainkan.

Pemilihan naskah Pintu Tertutup karya Jean Paul Sartre terjemahan Asrul Sani akhirnya menjadi pembelajaran bagi yang memainkannya. Ketika membaca latar belakang karakter Estelle, terdapat kesendirian, alienasi bahkan kesedihan ketika Estelle masih menjadi orang miskin yang harus yatim piatu sejak kecil dan mengurus adik laki-lakinya. Kemudian Estelle sebagai pribadi yang memperjuangkan kebahagiaan dirinya menempuh jalan dengan cara menerima lamaran dari laki-laki kaya. Estelle hanya ingin keluar dari kemiskinan kemudian dia mati dan berada di dalam neraka. Neraka dalam naskah Pintu Tertutup ini ternyata tidak terdapat alat-alat penyiksa dan dekorasi tempat yang dibayangkan manusia pada umumnya. Hanya ada beberapa perabotan dan tiga orang yang berada di dalamnya. Seperti yang dijelaskan di atas bahwa kehadiran orang lain pada akhirnya menjadi siksaan dan seperti berada di dalam neraka. Bagi penulis naskah sendiri orang lain atau kematian merupakan fakta-fakta yang tak terhindarkan dalam kehidupan manusia. Pemikiran seperti itu disebut Sartre sebagai faktisitas, fakta tersebut sebagaimana penjelasan lebih lanjut, tidaklah dapat "ditiadatakan", namun mampu sedemikian rupa "dilupakan", "diolah" atau "dimanipulasi" (Nugroho, 2013). Sehingga faktisitas tersebut bisa menjadi sebuah metode terapi guna menemukan proyek diri.

Pintu Tertutup sebuah naskah dari Jean Paul Sarte mengenai manusia dan dipentaskan menjadi pertunjukan teater tentu akan menjadi suatu pengalaman diri yang luar biasa baik bagi tim maupun bagi penonton.

Tujuan dari penciptaan pemeranan ini adalah :

a. Mengetahui karakter Estelle melalui analisis naskah dan analisis psikoanalisis.

b. Dapat memainkan karakter Estelle dalam naskah Pintu Tertutup Jean Paul Sarte Terjemahan Asrul Sani dengan pendekatan presentasi.

\section{Tinjauan Pustaka}

Penciptaan karya merlukan landasan teori sebagai acuan dan pendekatan sehingga karya tersebut dapat dipertanggungjawabkan secara ilmiah. Untuk mencapai tujuan penciptaan ini maka analisis naskah menggunakan teori yang mendukung mutlak diperlukan. 
Meskipun tokoh dalam Naskah Pintu Tertutup sudah mati dan berada di dalam neraka tetapi tetapi konflik yang di bawa adalah tentang kehidupan manusia. Misalnya persoalan Garcin yang tidak ingin dikatakan pengecut oleh orang-orang di bumi, masalah Estelle yang takut nama baiknya jatuh. Persoalan-persoalan tiap tokoh ini dapat ditemui dalam kehidupan manusia yang hidup.

Tokoh Garcin dan Estelle memiliki masalah karena tidak ingin mengakui dosadosanya dan terus berada dalam kecemasan. Tokoh Inez sendiri menyadari betul dirinya sudah mati dan tidak bisa berbuat apa-apa lagi. Inez merasa tenang dan menerima dirinya masuk ke neraka karena sudah menjadi pilihannya untuk menjadi yang dia inginkan.

Inez mengajak Garcin dan Estelle untuk sadar dan tidak menyesali perbuatannya. Kemudian dalam alur cerita mengharuskan mereka untuk kembali menceritakan masa lalu. Tokoh Inez yang sering memberi pertanyaan khususnya kepada Estelle. Dalam cabang ilmu pengetahuan yang dilakukan Inez adalah bagian dari Psikoanalisis.

Psikoanalisis merupakan sebutan untuk prosedur penyelidikan terhadap proses mental yang hampir tidak bisa diakses dengan menggunakan cara lain (Fodor, 2009). Psikoanalisis ini dicetuskan oleh seorang psikolog, Sigmund Freud. Suatu metode kejiwaan guna mengatasi neurosis dan psikosis dengan melibatkan permainan id, ego dan super-ego.

$$
\text { Ego dipaksa mengetahui }
$$

kelemahannya, ego berubah menjadi kecemasan: kecemasan realitas saat menghadapi dunia luar, kecemasan normal saat menghadapi superego, dan kecemasan neurotis saat berhadapan dengan kekuatan hasrat $i d$. Id adalah yang pertama ada. Ego tumbuh dan berkembang di luar $i d$, melewati pengaruh dunia luar. Insting dasar kita bermula di dalam id. Ego mewakili halhal yang berkaitan pertimbangan akal sehat dan kehati-hatian, sementara id mewakili hasrat yang meletup-letup.
Analisis bertujuan untuk memperlihatkan kompleks tekanan yang disebabkan oleh perasaan sakit yang berasosiasi dengannya, dan mengeluarkan tanda resistensi ketika terdapat upaya untuk mengangkat kompleks tersebut ke alam sadar (Fodor, 2009).

Karakter Estelle dibuktikan dalam naskah selalu melakukan penolakan terhadap realitas karena dirinya melakukan perbuatan dosa. Karena kebenaran yang terlalu menyakitkan maka Estelle berusaha untuk menutupinya. Pada adegan Garcin hendak membuka jas, tanpa sadar Estelle setengah berteriak mengatakan bahwa Garcin sangat tidak tahu aturan. Sikap Estelle kepada Garcin menjadi sangat kasar karena kehidupan dan aturan yang dijalani Estelle pada saat lalu. Kemudian mengingat bahwa perkataannya kasar dengan cepat Estelle meminta maaf dan menjelaskan dengan sopan.

Teori Psikoanalisis Sigmund Freud digunakan untuk mengetahui apa yang terjadi pada masa lalu dan sifat sebenarnya dan untuk mencari solusi atas berbagai hasrat dalam diri yang terkekang dari karakter Estelle.

\section{Metode}

Melalui teori Psikoanalisis Sigmund Freud, karakter Estelle bisa diketahui secara mendalam sebab telah diketahui halhal yang membentuk pribadi Estelle. Kemudian untuk mewujudkan karakter Estelle perlu metode penciptaan sehingga data-data mengenai karakter yang sudah diketahui dapat dimainkan dengan baik.

Karakter Estelle adalah karakter yang terdapat dalam manusia. karakter yang dapat dijumpai dalam kehidupan. Kehidupan yang diperlihatkan ke atas panggung menjadi presentasi dari contoh manusia, sehingga dipilih pendekatan presentasi. Pendekatan presentasi mengutamakan identifikasi antara jiwa si aktor dengan jiwa si karakter, sambil memberi kesempatan kepada tingkah laku untuk berkembang. Tingkah laku yang berkembang ini berasal dari situasi-situasi 
yang diberikan si penulis naskah (Sitorus, 2002).

Teori presentasi memungkinkan aktor memainkan peran menggunakan kepribadian manusia sebagai dasar metodenya. Kepribadian manusia ini terdiri dari tiga bagian penting yaitu fisikal, intelektual dan spiritual yang dalam akting presentasi disebut ekspresi, analisa dan transformasi (Sitorus, 2002). Pendekatan Presentasi tersebut dipilih sebagai metode penciptaan karakter Estelle dengan tahap:

\section{a. Analisis Naskah}

Analisis naskah ini bertujuan untuk mengetahui laku dan pesan yang harus aktor sampaikan. Aktor dapat mengerti cara menghidupkan karakter yang dimainkan, segala pesan yang tertuang dalam naskah dapat diwujudkan dalam laku aktor. Hal tersebut mutlak dilakukan oleh aktor.

\section{b. Mengolah Dialog}

Agar dapat menyampaikan pesan, cara melafalkan dialog juga harus diperhatikan. Cara melafalkan dialog ini bisa dengan cara patah-patah, tempo cepat, lambat, volume suara keras, pelan, marah, senang dan sedih. Seluruh latihan mengolah dialog ini dapat membantu menyampaikan pesan. Misalnya, dialog diucapkan patahpatah yang biasa diidentifikasi sebagai cara dialog orang yang gugup atau takut.

\section{c. Tubuh, Rasa dan Suara}

Setelah mengolah dialog, aktor harus senantiasa mengolah tubuh, perasaan dan suaranya. Aktor harus bisa menelaah ke dalam raga dan sukmanya, karena di dalam sukma terdapat unsur-unsur emosi, kemauan, semangat, pikiran dan fantasi. Dalam raga ada tubuh, gerak, pernafasan, kekuatan (Anirun, 1998). Maka tahapantahapan tersebut harus dilakukan agar aktor siap menjalani latihan untuk membentuk karakter tokoh yang diharapkan. a. Pencarian Sosiologis Karakter

Pengamatan pada tingkah laku tokoh yang akan dimainkan, cara bicara dan gesture bisa dilakukan dengan mempelajari biografi pengarang, kejadian yang terjadi selama kurun waktu tiga tahun sebelum dan sesudah naskah dibuat, film, musik, fashion dan juga foto yang berkaitan dengan naskah.

\section{d. Transformasi}

Proses pertama dari transformasi adalah memberi fokus kepada energi yang sudah dimiliki aktor. Dia harus mampu menyetir dirinya menuju satu tujuan tertentu. Usaha memfokuskan energi ini adalah usaha menyerahkan diri sepenuhnya kepada aksi dramatis naskah karena proses transformasi adalah proses memfokuskan diri yang dilakukan dalam latihan, dari hari pertama sampai akhir pertunjukan (Anirun, 1998).

Hasil keseluruhan latihan mulai dari menghafal naskah, mengolah dialog, seluruhnya difokuskan pada satu tujuan karakter. Proses transformasi ini bisa dilatihkan ketika sendiri dan juga dengan lawan main yang kemudian di presentasikan dalam run dan akan di evaluasi untuk kemudian di detailkan kembali melalui cut to cut. Garis besar metode penciptaan ini diharapkan dapat membantu aktor agar dalam menciptakan suatu karakter yang lengkap.

\section{Pembahasan}

Analisis karakter dalam naskah yang telah dilakukan menghasilkan profiling karakter Estelle sebagai berikut:

Estelle adalah wanita dengan usia sekitar 25 tahun, jenis kelamin perempuan, memiliki kornea mata hijau, dan badan ramping. Estelle memiliki status sosial tinggi karena statusnya sebagai istri lakilaki kaya. Hobinya adalah menghadiri pesta-pesta dan ia berasal dari Paris. Estelle memiliki pandangan bahwa hidupnya harus penuh dengan kesenangan dan terus mencari kebahagiaan. 
Pada adegan Estelle melihat ke alam kehidupan, Estelle melihat acara pemakaman dirinya kemudian dia melihat bahwa sahabat baiknya tidak menangis. Inez sebagai tokoh yang melihat ekspresi kesedihan Estelle kemudian bertanya melalui dialog 113 ("Inez : Apa kau menderita sekali?"). Estelle kemudian menjawab bahwa dirinya hanya separuh sadar. Keadaan Estelle mengalami sebuah perasaan cemas. Estelle merasa bahwa dengan mengatakan bahwa dia sangat menderita karena sahabatnya tidak menangisi kematiannya, maka pencitraan terhadap dirinya yang berasal dari orang kaya, populer, banyak teman akan hilang.

Hal ini juga terjadi pada adegan :

142. Estelle : (Melihat pada kedua mereka dengan mata orang heran) Aku betulbetul tidak mengerti kenapa kita bertiga ditempatkan bersama-sama. Tidak masuk akal sama sekali.

143. Inez : (Menahan ketawa) Apa katamu?

144. Estelle : Aku memandang pada kalian berdua dan berfikir, kita akan tinggal bersama... Edan sekali. Aku mengira akan ketemu kawan-kawan lama, saudara-saudara.

145. Inez : Ya, kawan-kawan lama yang cantik - dengan muka berlubang.

146. Estelle : Ya, dia juga. Ia pintar sekali berdansa tango. Seperti ahli dansa professional... tapi kenapa, kenapa justru kita yang ditempatkan bersama?

147. Garcin : Barangkali hanya kebetulan. Mereka menempatkan orang sesuai dengan urutan kedatangan mereka. (Pada Inez) Kenapa kau ketawa?

148. Inez : Karena lucu kedengarannya, kau dengan " kebetulan " kau. Seolaholah ada disini yang bersifat kebetulan. Tapi barangkali kita harus meyakinkan diri kita sendiri.

149. Estelle : Aku bertanya-tanya. Apa kita tidak pernah bertemu sewaktu kita hidup?

Pada adegan tersebut Estelle telah berada pada keadaan dimana dirinya cemas berada di dalam neraka dan Estelle mengetahui betul dosa-dosanya. Ketika ego dipaksa mengetahui kelemahannya, ego berubah menjadi kecemasan: kecemasan realitas saat menghadapi dunia luar, kecemasan normal saat menghadapi superego, dan kecemasan neurotis saat berhadapan dengan kekuatan hasrat id (Fodor, 2009).

Ego yang dikeluarkan oleh Estelle akhirnya tidak dapat melawan id yang sudah dia lakukan sehingga reaksinya akan menyalahkan orang lain dan berlebihan. Estelle selanjutnya menyalahkan orang lain karena salah memasukkannya ke dalam neraka, hal tersebut ada di dalam naskah dengan munculnya dialog :

175. Inez : Apa yang telah kau lakukan? Maksudku, kenapa kau dikirim kemari?

176. Estelle : Itulah. Aku sendiri tidak tahu. Sedikitpun aku tidak tahu. Malahan aku berfikir, barangkali orang sudah khilaf. (Pada Inez) Jangan tersenyum. Coba bayangkan berapa banyak orang yang yang jadi absen setiap hari. Beribu-ribu. Mungkin sekali mereka diatur oleh - kau tahu maksudku - oleh pegawai rendahan. Pegawai-pegawai bodoh yang tidak mengerti pekerjaan mereka. Jadi mungkin sekali mereka melakukan kesalahan... Jangan tersenyum. (Pada Garcin) Kenapa Tuan tidak bicara? Kalau mereka salah mengenai aku, mereka juga mungkin salah mengenai Tuan. (Pada Inez) Kau juga. Pendeknya, apa tidak lebih baik kita anggap saja kita ada di sini karena kesalahan?

Estelle mengeluarkan reaksi yang berlebihan dengan menyalahkan orang lain ketika terdesak oleh pertanyaan yang semakin membuatnya menjadi cemas. Melalui kalimat Estelle pada dialog 178 juga akhirnya ditemukan data mengenai masa lalu Estelle yaitu : Estelle memiliki seorang adik laki-laki, Estelle telah yatim piatu sejak kecil, Estelle harus bekerja untuk mencukupi kebutuhan hidup, Estelle dijodohkan dengan laki-laki kaya, suaminya enam kali lebih tua dari umurnya, delapan tahun setelah pernikahannya Estelle bertemu dengan laki-laki yang lebih muda dari suaminya dan mencintainya, Laki-laki tersebut mencintainya dan mengajaknya lari. 
Setelah informasi data tersebut diketahui, pada naskah juga dituliskan bahwa Estelle tidak memberitahu keputusannya apa dia juga mencintai lakilaki muda tersebut.

Kekuatan id mengekspresikan tujuan yang sebenarnya dari kehidupan individu, yang terdiri dari pemuasan terhadap kebutuhan-kebutuhan pembawaan lahir. Id sama sekali tidak dibebankan terhadap tugas untuk menjaga diri agar tetap hidup atau untuk mempertahankan diri dari bahaya yang ditimbulkan oleh kecemasan. Itu merupakan tugas ego (Fodor, 2009).

Sehingga pada informasi tersebut, Estelle sebenarnya telah menyatakan bahwa dirinya ingin menjadi orang kaya dan berstatus sosial tinggi. Id dalam diri Estelle telah membuat diri dirinya terus memuaskan keinginannya. Kemudian ketika Estelle memiliki hasrat untuk bersama laki-laki yang usianya setara dengan dirinya bernama Roger. Hal tersebut terjadi karena hasratnya untuk memiliki Roger tidak bisa terpuaskan karena Estelle sudah memiliki suami.

Pada data lebih lanjut juga diketahui bahwa Estelle juga memiliki pacar yang usianya jauh lebih muda yang bernama Peter. Karena Estelle sadar dirinya tidak bisa lepas dari suaminya yang menyayanginya maka Estelle membentuk dirinya sebagai wanita yang cantik dan pantas untuk dicintai siapapun. Hal tersebut dilakukan Estelle melalui menghadiri pesta dan juga pengakuan dari Peter yang memujanya.

Dalam psikoanalisis hal tersebut terjadi karena Estelle merasa tidak mendapatkan kepuasan dari pernikahannya, tetapi dia juga bahagia karena memadai orang kaya. Estelle melakukan sikap narsissisme (yaitu tidak merasa butuh terhadap objek) dan egoisme secara bersamaan. Seseorang mungkin secara mutlak egois tetapi memiliki keterikatan libido yang kuat dengan objek, sejauh pemuasaan libido dalam sebuah objek merupakan kebutuhan egonya: egoismenya kemudian akan melihat bahwa keinginannya terhadap objek tidak melukai egonya (Puspitorini, 2002).

Menjadi wanita yang suka merayu, datang ke pesta, menunjukkan kecantikan merupakan salah satu cara Estelle untuk menyalurkan hasrat dirinya yang tidak bisa memiliki Roger. Ditambah dengan ditemukan data bahwa Roger berasal dari keluarga miskin.

Pada kehidupan Estelle, diketahui bahwa Estelle pada akhirnya memiliki anak dari Roger. Hasrat dalam diri Estelle ternyata lebih besar sehingga Ego dalam dirinya tidak cukup untuk memendam hasratnya. Estelle sendiri memiliki data bahwa sejak kecil harus bekerja sehingga tidak ada pendidik atau orang tua yang mengajarinya norma-norma sehingga menjadi Superego. Kehidupan orang kaya juga membuat Estelle menjadi pribadi yang selalu yakin akan kebenaran dirinya.

Estelle juga menyukai Roger, cinta dalam bentuknya sendiri merupakan gelora kerinduan dan kehilangan, menurunkan pandangan terhadap diri sendiri, mencitai, dicintai, memiliki obyek tercinta, dan mengaguminya. Karena adanya kecenderungan seksual yang dilarang tersebut, obyek menggambar bagian libido ego narsistik pada dirinya sendiri. Ini merupakan kondisi ketika hanya ada ruang bagi ego dan obyek (Fodor, 2009).

Melalui analisis psikoanalisis dapat diketahui bahwa kondisi psikologi Estelle menjadi sangat narsis, Estelle juga bisa berteriak dan memperlihatkan sikap tidak sopan karena masa lalunya yang miskin dan usaha keras menjadi orang kaya, Estelle juga mengeluarkan sikap sombong karena mempertegas status sosialnya yang sudah berubah menjadi kaya, Estelle memiliki kondisi psikologis yang buruk karena keinginan atas hasrat terhadap Roger tidak bisa dipenuhi.

Hasrat tersebut akhirnya oleh Estelle diwujudkan, tetapi setelah dia mendapat anak dari Roger. Estelle kembali menghadapi kenyataan bahwa suaminya tidak mengetahui perbuatan Estelle. Menyandang status sosial tinggi dan 
terhormat membuat Estelle menjadi pribadi yang tega untuk membunuh anaknya.

Psikologis Estelle pada saat itu pasti sangat terganggu karena sejak awal dia tidak memiliki Superego untuk mengalahkan hasratnya. Kemudian dalam naskah cerita terus berlanjut setelah Estelle hancur dengan kenyataan hidupnya. Tetapi Sartre menawarkan hal lain yang sebelumnya diulas dalam tema dan amanat. Orang lain adalah neraka merupakan fakta kehidupan yang tidak dapat dihindari dalam kehidupan. Kerangka psikoanalisis Sigmund Freud bagi Sartre juga merupakan salah satu kerangka eksistensialis. Jika psikoanalis berusaha untuk mencari solusi atau jalan atas berbagai hasrat dalam diri yang terkekang. Maka Psikoanalisis Sartre berusaha mencari multirelasi antara suatu diri dengan dirinya sendiri. Pada naskah Pintu Tertutup Estelle dan Garcin pada akhirnya mengetahui bahwa mereka telah melakukan kekonyolan karena merasa cemas dengan dosa mereka, sedangkan mereka sudah mati.

Hasil analisis tersebut kemudian melengkapi fisiologis, sosiologis dan psikologis karakter Estelle sehingga aktor sudah mengetahui karakter Estelle. Langkah selanjutnya adalah aktor harus melakukan pelatihan keaktoran yang bertujuan untuk melatih tubuh, suara dan sukma agar mampu memainkan peran Estelle. Aktor juga harus menghadirkan imajinasi untuk membayangkan karakter dan situasi yang diperankan.

Proses keaktoran juga harus melewati langkah cut to cut dan run dimana hasil latihan akan dimainkan di depan sutradara. Kemudian jika ada laku dari aktor yang dirasa harus dilatihkan kembali, maka dalam cut to cut aktor akan berlatih adegan yang kurang tersebut secara detail dan berulang-ulang.

\section{Simpulan}

Tokoh Estelle dalam naskah Pintu Tertutup selalu terlibat dalam keadaan harus mengingat masa lalu. Estelle selalu melakukan penolakan terhadap realitas bahwa dirinya telah membunuh bayinya. Ego yang dilakukan oleh Estelle ini berawal dari masa kecil Estelle yang ingin kaya dan mempunyai suami yang sesuai dengan usianya. Hasrat dalam diri Estelle ternyata lebih kuat sehingga Ego yang terbentuk juga sering mendukung hasrat Estelle.

Sartre sebagai penulis yang menciptakan tokoh Estelle kemudian menawarkan solusi yang dinamakan proyek diri. Pandangan tentang masa depan memiliki pengaruh yang lebih besar ketimbang masa lalu. Masa lalu merupakan kenyataan yang telah terjadi dan hanya bisa dimaknai. Sedangkan masa depan belum terjadi.

Seperti dalam naskah bahwa Garcin menegaskan bahwa "Neraka adalah Orang Lain". Orang lain bagi Sartre memang merupakan fakta-fakta dari kehidupan, begitu juga kematian. Sebagai manusia yang hidup seharusnya bebas, tanpa kecemasan dan selalu berusaha membuat diri yang lebih baik untuk masa depan.

Seseorang yang hidup secara otentik adalah mereka yang menyadari bahwa eksistensinya di dunia adalah bebas. Keberadaan fakta kehidupan seperti waktu, masa lalu, tempat, orang lain selalu membuat konstruksi mengenai kebaikan, kecantikan, kemajuan, kecanggihan dan lain sebagainya. Jika manusia tidak memiliki eksistensi maka dia akan terjerat dalam konstruksi dari orang lain. Sehingga disinilah letak masa depan manusia. Manusia selalu berada dalam usaha untuk menemukan pribadi yang dipilihnya secara bebas. Kebebasan dapat menjadi Anugrah, tetapi bisa juga menjadi bencana tergantung manusia yang akan menentukan masa depannya.

Pesan dari naskah dan interpretasi pencipta kemudian diwujudkan menjadi sebuah pertunjukan teater. Pertunjukan ini berasal dari naskah Pintu Tertutup atas keinginan pencipta sebagai aktor dan memilih untuk memainkan tokoh Estelle Rigault. Tokoh Estelle yang pandai menutupi kesalahannya dan menggunakan 
cara merayu untuk mendapat keuntungan menjadi daya tarik sendiri untuk penciptaan karakter. Setelah mengetahui karakter yang akan dimainkan melalui analisis naskah, pencipta sebagai aktor harus mengetahui betul tugas dan tanggung jawab aktor. Melalui metode presentasi aktor melakukan transformasi dengan cara mengolah dialog, berlatih raga, sukma dan suara.

Titik paling terpenting untuk memainkan karakter tokoh terletak pada pengetahuan aktor untuk menganalisis naskah, kelengkapan aktor mengetahui karakter tokoh yang terdiri dari fisiologis, sosiologis dan psikologis. Kemudian ketiga dimensi tokoh tersebut berfungsi sebagai capaian aktor merubah kebiasaan aktor menjadi tokoh yang akan dimainkan. Proses merubah tersebut terdapat dalam proses transformasi yang harus didukung oleh tubuh yang siap, sukma yang tenang dan fokus, keterampilan dan juga konsistensi dari aktor untuk menjadi karakter yang akan dimainkan.

Kemudian dengan memilih orientasi bentuk pertunjukkan ekspresionis, pencipta akan memikirkan seluruh elemen-elemen pertunjukkan. Mulai dari setting panggung, pencahayaan, kostum, musik sampai tata rias. Elemen-elemen pendukung tersebut harus memikirkan unsur-unsur garis yang didistorsikan sehingga akan menciptakan kesan ekspresionis.

\section{Daftar Pustaka}

Anirun, S. (1998). Menjadi Aktor. Bandung: Rekamedia Multi prakarsa.

Fodor, N. (2009). Kamus Psikoanalisis Sigmund Freud. Yogyakarta : eNusantara.

Freud, S. (1920). Psikoanalisis Sigmund Freud: a general introduction to psychoanalysis. (Puspitorini, I., Trans). Yogyakarta Ikon Teralitera. (Original works published 1920).

Nugroho, B.W. (2013). Orang Lain adalah Neraka! Sosiologi eksistensialisme Jean Paul Sartre.

Sartre, JP. (1989). No Exit And Three Other Plays. New York: Vintage International.

Sitorus, D. E. (2002). The Art Of Acting Seni Peran untuk Teater, Film dan $T V$. Jakarta : Gramedia. 